\title{
Anaphylaxis Reaction to Samsum Ant (Pachycondyla Sennaarensis): A Case Series Study
}

\begin{abstract}
Purpose: Anaphylaxis is a life-threatening hypersensitivity reaction. The present study als ned to investigate the cases of anaphylaxis to ant stings in Iran to determine the chara te. ${ }^{\prime}$. $c$ cs of patients, geographical distribution and the type of ants that cause anaphylaxis. aticnts and Methods: Patients with a history of anaphylaxis to ant sting underwent skin : il : ry test with extracted substance from Solenopsis Invicta. Samples of ants were collected fr $r \mathrm{~m} h$ sites where each patient was bitten and their species were identified by a medical entc nol, gist. Results: Nineteen patients (mean age: 26.2 years; range: 4-48 years) were inclu ${ }^{\prime} \cdot \mathrm{a}$ : $\eta$ the study. Most patients (89.5 percent) were female. The lower limb was the most comran site of the sting and most stings had occurred in the morning (31.6\%) and evening (31.6\%). Skin manifestations were the most common clinical symptoms (94.7\%). Most cases of stit $_{2}{ }^{-\varsigma}$ were observed in the Hormozgan province $(89.5 \%)$ located in southern Iran. Sixteen $p^{\text {pties }}=$ had positive skin prick test for ant venom. All collected ants that caused anaphylaxis velo iged to the Pachycondyla Sennaarensis species. Conclusion: Ant sting anaphylaxis is nct uncu ?mon in Iran, especially in its southern regions. All cases of anaphylaxis in this study were due to samsum ant sting (Pachycondyla Sennaarensis), which is a species similar to 'he fire ant (Solenopsis Invicta). Allergy skin testing with fire ant extract was positive . na ..elpful in identifying samsum ant allergy in all cases.
\end{abstract}

Keywords: Anaphylaxis, Ant Venoms, Insects Aller ,y

Impact Statement: This study is the first case se 1e, report from anaphylaxis to ant sting in Iran and all cases of anaphylaxis in this study were c e w samsum ant sting.

\section{Introduction:}

Anaphylaxis is an acute systemic hyper $\bullet_{n}$, itivity reaction caused by the release of various mediators from mast cells and basophis a an 1 can be induced by various triggers, including foods, drugs, and stinging insects (1-3) Stinging insects of the Hymenoptera order can cause anaphylaxis. Systemic allergic re ${ }^{+}$ions to insects stings are reported by up to $3 \%$ of adults and about $1 \%$ of children have a med ca . history of severe reactions to insect sting (4). In a crosssectional study of Bemanian $t$ al., the frequency of anaphylactic reaction in adults and children was 169 and 46 cases $p_{\iota_{1}} \cdot 0 v, 000$, respectively (5). There are three families of clinically

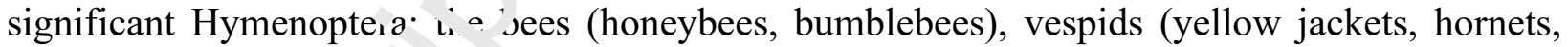
wasps), and stinging $\cdot n t s$. There are several species of ants that their stings can lead to anaphylaxis, including turmicidae such as fire ants (Solenopsis Invicta), Myrmecia spp, Pogonomyrmex $\mathrm{s}^{r} \mathrm{p}, \mathrm{i.} \mathrm{d}$ Pachycondyla $\mathrm{spp}$ (6). Fire ants are responsible for most allergic reactions to ant s.ilg, in the United States (7). Jack jumper (Myrmecia pilosula) in Australia, Pogonomyrmex sp - in Canada and Pachycondyla spp in Asia and the Middle East are the most common ca so of ant stings hypersensitivity (8-10). In Africa and the Middle East, reported cases of an sting anaphylaxis are almost always caused by Pachycondyla (Brachyponera) Sennaar $n_{\text {s1: }}$ (10). There have been no reports of anaphylaxis to ant in Iran until now. In this study, re piesent the first report of anaphylaxis to ant in Iran over 10 years as a case series. 


\section{MATERIALS AND METHODS}

This study was conducted at the Allergy Research Center of Rasool-E-Akram Hos ${ }_{1}^{\text {ital in }}$ Tehran, Iran. The study was conducted in full accordance with the principles outli ed in the Helsinki Declaration of 1975. The study protocol was reviewed and approved by the siuman Research Ethics Committee of Iran University of Medical Sciences (Approved Number: IR.IUMS.FMD.REC 1394.2272). All participants signed an informed consent $\mathrm{o}^{r} \mathrm{~m}_{\mathrm{l}}$ after being informed about the study protocol.

According to scattered reports of anaphylaxis to ant stings in Iran, $a_{1}^{2}+r$ ontacting Iranian allergists, they were asked to refer all cases of ant anaphylaxis from $200+\therefore \angle 014$ to the Allergy Research Center of Rasool-E-Akram Hospital in Tehran and a private $a 1 \_r c, y$ clinic in Yazd. All patients who had a history of generalized systemic allergic reaction ${ }^{+} \mathrm{h}$ ar, and their history were compatible with clinical criteria for the diagnosis of anaphylaxi $w$ re included (11). Subjects were excluded from the study if investigation based on the patit. 't's history indicated that no systemic reaction had occurred or that the ant sting was not ${ }^{+}$e cause of the reaction. At study enrollment, patients' demographic and clinical characteristic, 1hcluding their age, sex, time of the incident, geographical location, clinical manifesi ${ }^{*}$ ic.' $c$ of the reaction, any history of hypersensitivity to ant bites, medical history, and history of drug or alcohol use before the reactions were recorded. In addition, the records $o^{f} p$-tients at emergency department, where patients were admitted in case of hypersensitivity $r_{t}{ }^{+}$ons, were reviewed and the data were integrated. The severity of the anaphylactic re ${ }^{4} \mathrm{O}$ for each individual was rated as mild, moderate, or severe according to the criteria puiv ' hed by Brown (12). This rating is based on the clinical manifestations of the anaphylactic $r^{c}$ act $n$ and the organs involved in the anaphylaxis. We asked a family member or friend of in pu ticipants who had no history of ant allergy to collect four samples of ants from each $\mathrm{p}^{\mathrm{l}_{1}} \cdot \mathrm{v}$ here the patient reacted. The ants' specimens were identified by a medical entomologist $r$ gars ing their unique entomologic phenotype. In addition, participants were asked to identify $t^{\prime}$ e art responsible for their reaction based on the appearances of the ants.

All subjects underwent skin privi test with extracted substance from Solenopsis Invicta (commercial solutions of Hoi "ister-Stier Allergy Company, Chicago, USA). The tests were performed by an allergist $>\mathrm{col}$ ding to the manufacturer's recommended protocol at the hospital. Patients with negative $\mathrm{r}^{\wedge} \mathrm{s}_{\mathrm{r}} \sim \mathrm{n}_{\mathrm{s}} \cdot$ in skin prick test underwent intradermal skin allergy test with ten times diluted extract $A^{\prime 1}$ tests were done with histamine chloride $10 \mathrm{mg} / \mathrm{ml}$ as positive and sodium chloride 0.9 ( $⿱$ as negative controls. The test response was read after 15 minutes. A wheal diameter caused $\mathrm{l}^{\mathrm{y}^{+}}-$ted allergens more than 3 millimeter compared to the negative control was considered as a $r$ 'siive response and sensitization to that allergen.

\section{Statistical 8...'lysis}

Statistic natysis was performed using Stata statistical software (Stata 13, Stata Corp, Texas, USF : D s s riptive data were expressed as mean (standard deviation) or median (range) for contin ' O s $^{3}$ variables and number (percent) for categorical variables, respectively. Data regarding fea. 'res of sting, clinical manifestation, medical history and severity grading of anaphylaxis were 
further summarized in respective tables.

\section{Results:}

Nineteen participants (mean age: 26.2 years; range: $4-48$ years) met the inclusion c. :əria. The majority of subjects ( 17 out of 19 ) were female. Data related to occurred reaction s ifl ir ant sting, such as reaction characteristics, geographic locations, and anatomical locatio $\mathrm{s}$, a e presented in Table I. Most stings had occurred in the morning ( $31.6 \%)$ and evening $(31.6 \%$, (Table I). Most cases of stings were observed in Hormozgan province located in the sorth \& f Iran (89.5\%) and the capital of Hormozgan province in Bandar Abbas (47.4\%) (Figure : anc 2). The lower limb was the most common site to be bitten (Table I). Each patient had a. average history of 4.2 previous systemic reactions due to ant sting (range 2-10 times). Ant siag in most cases led to a systemic reaction (94.7\%), and local reaction occurred only in - 3\% of patients. According to patients' medical records, $78.9 \%$ had a history of at least or 2 atopı disease. Allergic rhinitis $(73.3 \%)$ and asthma (15.8\%) were the most common allergir $\gamma_{L}$ ases among the participants. In $31.6 \%$ of cases, subjects had a history of underlying rise 'se, he most common of which was cancer. Family history of patients showed that $52.6 \%$ of su hiects had a family history of allergic disorders. Among family members, the prevalence o allergies was higher in mothers $(21.1 \%)$ and asthma was the most common allergic disease (21.1\%). A summary of the participants' medical history is provided in Table I.

The mean time interval between stings to the firs - linical manifestation was 3.7 minutes (range 1-10 minutes). Information on the clinical nan festations after sting and its management are presented in Table II. According to t'se rec irds of patients admitted to the emergency departments, skin manifestations were the - sst common clinical symptoms, which occurred in $94.7 \%$ of patients (Table II). Pruritus, fl'shing, and dyspnea occurred in $89.5 \%, 73.3 \%$, and $73.7 \%$ of subjects, respectively. I'one of the participants had cyanosis, abdominal cramp, bronchospasm, or incontinence $\left(F_{1 \xi} \cdot\right.$ re 3$)$.

After the sting incident, Patients were evaluated in terms of actions after the sting. Most cases (89.5\%) referred to the emargc - $-y$ department and two patients had taken oral antihistamines themselves and did not go $\rightarrow$ th $\mathrm{e}$ emergency department. At the time of the ant sting, only $21.2 \%$ of patients had epineph inc, bu none of them used it at the time of the attack. Of the 15 patients referred to the emerg sacy department, $88.2 \%$ responded well to the first dose of epinephrine and $11.8 \%$ required repe ter epinephrine (Table II). None of the patients needed cardiopulmonary resuscitation. The v rage length of stay in the emergency room was 2 hours (range 1 to 5 hours). Out of 1, natients referred to the emergency department, three patients (17.6\%) needed to be hospitalizu After discharge, EpiPen (self-injecting epinephrine) was prescript to only four patients an no action plan for anaphylaxis was given to any patient.

Accrrdi.ys tr Brown's model for classifying the severity of anaphylactic reactions (12), moderate reacti $n_{\text {. }}$ were the most common anaphylactic reactions $(57.9 \%)$. The results of grading the se. गii, of anaphylactic reaction in participants are presented in Table II. 
Participants' allergy to ant venom was confirmed by skin allergy tests. Initially, all patients underwent skin prick test (SPT). The SPT results showed that 16 out of 19 patients have $\mathfrak{p}$ os. ive SPT for ant venom. The other three patients were then tested by intradermal test and wra $:$ und that they were also allergic to ant venom. Two patients showed a systemic reactic' $d$ 'rin'; skin tests and were treated immediately.

A medical entomologist evaluated the collected ant samples to determine the spr ci is of ants that caused the allergic reactions. He confirmed that all ant samples belonger. to i achycondyla Sennaarensis species (Figure 4).

All patients were asked to receive immunotherapy and $42.1 \%$ accepted un pioposed treatment. Patients stated that the most common reason for not participating in imm n $^{\text {n }}$. herapy was the high cost of treatment (Table II). Venom immunotherapy was performt $d$ with the GREER ${ }^{\circledR}$ (Allergenic extracts - Ant Fire, Solenopsis Invicta; Lenoir, Unit cu States of America). Of the eight patients who underwent immunotherapy, 50\% had adverse "actions to immunotherapy. The most common complication was a local reaction at the liection site. Of the eight patients treated with immunotherapy, six were re-sting by ants, rı only one developed anaphylaxis (Table II)

\section{Discussion:}

The prevalence of anaphylaxis in the US popui, ion is estimated at $1.6-5.1 \%$ (13). Anaphylaxis to insect stings is responsible for $20-30 \%$ of s il . naphylaxis cases referred to emergency services $(13,14)$. It is estimated that about 0.4 to $0 . \%$ of children and 2 to $3 \%$ of adults experience a systemic reaction to insect stings during $\left.t^{\prime}, \mathrm{e}\right)$ : lifetime $(15,16)$. Anaphylaxis following insect stings is a major challenge for allergist.. The mortality rate from anaphylaxis due to insects sting is reported to be approximately 0.1 c'wes $^{2}$ er million population (17).

Some ants are in the group of sti $i \eta_{\mathrm{f}}$ insects. However, in a small number of ants, their stings cause allergic reactions (18). P ${ }^{\prime} c^{\prime} ı$ ycondyla Sennaarensis (PS) is an ant species widely distributed throughout sub- haran Africa and the Middle East $(19,20)$. In some countries around the Persian Gulf, tr el have been reports of anaphylaxis due to the sting of PS $(21,22)$. In a case report from $\mathrm{S}^{\prime}{ }^{\prime} \mathrm{a}_{1}{ }^{\prime}$ 'sabia in 2009 by AlAnazi et al., they reported four patients with anaphylaxis due to PS ? 2). They described that PS ants, like fire ants, inject their venom with a sting and do not bite In 'ran, the presence of PS was first reported in 2004 by Akbarzadeh et al. in Sistan and Balu shesun (a province in southeastern Iran). They described the ant's morphology with a punctuate ${ }^{-} \mathrm{h}$ 'ad and chest, a mandibular triangle, and seven teeth (23). In a study conducted by Dakı :a et al. In Iran, they found that PS was more prevalent in Iran, especially in the south $(2 \uparrow$. Most reported cases of ant stings in Iran were in Hormozgan province in southern Iran and $m^{-t}$ of them were from Bandar Abbas city in this province. By comparing the distribut $c a$, f PS ants in Iran as mentioned and the distribution map of ant bites in this study (Figu $e 1$ and 2), we understand that they are in the same areas. Khoobdel and his colleagues 
claim that shipping to southern countries around the Persian Gulf may be the cause of the PS entering Iran (25).

In a study by Nikbakht et al. in 2009, they claimed that there was no report of ar apı rlaxis following PS stings from Iran until that time. Based on their research in the biology a. $\gamma_{2}$..umical diversity of PS abdominal glands, they explained the lack of anaphylaxis witin : $1 \mathrm{w}$ protein content in the abdominal glands of PS in Iran (26). Here, we report 19 cases $r_{1}$ naphylaxis following PS sting, which is the largest report on this issue from the Middle rast. ivlost cases of anaphylaxis to the PS sting lived in southern Iran.

The mean age of patients in our study was 26.2 years and most cases $w-14$ tenale (17 out of 19 years). The mean age of patients in other studies of anaphylaxis to insec, st.ngs in Australia and Spain were 46 and 40 years, respectively $(8,27)$. Comparing the $m$ 'an i ze of the population of Iran and other countries in which the above studies have been pe 10 ned (Iran $=28.3$, Australia $=38.3$ and Spain $=41.6$ ) shows that the population of Iran is you ${ }_{2}{ }_{-} i$ than Australia and Spain. It may be explained why patients' mean age in our study wa- lower than other studies. In most studies of anaphylaxis to insect stings, there was no signifir an aifference in prevalence between men and women $(12,28-30)$. In our study, the preva ${ }^{2}, c_{-}$anaphylaxis to insect bites was significantly higher in women. It is difficult to explain the 1 ason for this observation due to the small number of cases.

In the present study, most stings occurred in the r 10 . ring and evening. In a survey by Khoobdel et al. on the biological behavior of ants in the tru $u_{r}^{-}-$s and subtropics, they explained that ants leave their nests shortly before sunrise and $\ldots$ rk for several hours as the earth warms. They return to their nest, and if they are far awav, . hey hide in the hole of the earth and resume their activity in the evening (25). This behar ir : ff the ants may explain why most of the stings occurred in the morning and evening.

In current study, the lower limb wa the most common anatomical site of the sting. In the study of Khoobdel et al. on ant bites in $\quad$ hu-iMusa Island, in the south of Iran, the lower limb was also the most stinging site $(50.7 \%)(25)$. It is probably because the lower limbs are the most accessible part of the body $\mathrm{fc}$ ants.

Skin manifestations were the nost common clinical manifestations in our study, followed by respiratory, cardiovasci la $a_{1}, n_{n}$ rological, and gastrointestinal manifestations, respectively. In a survey conducted by $\mathrm{J}_{\mathbf{L}}$ ' nongsananuruk et al. in Thailand on the characteristics of patients admitted with anaph. 'lax s, the most common manifestations were cutaneous (86\%), respiratory $(80 \%)$, Cardiovas $2 י^{\prime} \cdot(52 \%)$ and gastrointestinal (36\%), respectively (29). In another study by Brown et al. on 11 i patients with anaphylaxis in Australia, pruritus (73\%), erythema (48\%), angioedema (3,\%) and dyspnea (29\%) were the most common symptoms (12). In our study, pruritus, d. spn $\mathrm{a}$ and flushing were the most common symptoms. The order of common manifest $\lrcorner$, $\backslash n$ s in our study seems to be almost the same as in Brown's and Jirapongsananuruk's stud - It a ddition, three patients (17\%) of all our subjects required hospitalization, which is in line with the result of Jirapongsananuruk's study, where $12 \%$ of patients with anaphylaxis were

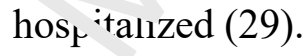


On average, the patients had a history of four-time stings leading to anaphylaxis in their history. A study by Webb et al. on anaphylactic patients showed that more than half of the $\mathrm{c} d \mathrm{~d}_{\iota}$ nts experienced more than three episodes of anaphylaxis (30).

In our study, $78.9 \%$ of patients had a history of atopic disorder. Allergic rhinitis, si....1a and urticaria were the most common diseases in $73.7 \%, 15.8 \%$ and $10.5 \%$, respectively. ' $n$ tne study of Jirapongsananuruk et al. in anaphylactic patients, $52 \%$ of cases had a history of a spy and the most common atopic diseases were asthma (26\%), allergic rhinitis (20\%) and urug allergies $(16 \%)(23)$. In another study by Web et al., anaphylaxis was more common in . ‘ pic patients, in which $54 \%$ of cases with exercise-induced anaphylaxis and $50 \%$ of patien ' with food-induced anaphylaxis had a history of atopic disorders (30).

In a study by González-Pérez et al., the incidence of anaphylaxis vas iigher in patients with asthma than in patients without asthma, and this rate was high i i severe asthma (31). In a patient with asthma, special attention should be paid to controlh. ? respiratory manifestations. Several studies have shown that inadequate treatment of ast ${ }^{h}$ ma is a significant risk factor for severe anaphylaxis $(32,33)$.

Alcohol and drug use before anaphylaxis may affect nt reverity of attacks (34). In our study, no one had consumed alcohol, and $15.8 \%$ of them har L' $^{1}$, n drugs such as aspirin, ibuprofen, and cetirizine. In the study of Wölbing et al. regardi $g$ th a effect of cofactors on anaphylaxis, they found that the use of alcohol and drugs (such as NSAIDs) can cause a more severe reaction with a small amount of allergen and reduce ne interval between exposure to allergens and anaphylaxis (35).

Regarding the underlying disease, $3 \frac{1}{.0} \%$ of the evaluated patients had underlying disease, including cancer $(10.5 \%)$ (breast $a_{1}{ }^{2}$ uterine cancer), cardiovascular diseases (5.3\%), thalassemia (5.3\%), Favism (5.3\%) anc Diabetes $(5.3 \%)$ In the Jirapongsananuruk's study of anaphylactic patients, $31 \%$ of th $m$ ' ad an underlying disease, which the most common disease were: cancer (11\%), cardiovascula $\cdot$. seases $(7 \%)$ and neuromuscular diseases (6\%) (29). Cancer and cardiovascular disease $a_{r_{n}}$ near to be the most common underlying diseases in patients with anaphylaxis.

We asked patients abc' $t$ th history of ant stings without anaphylaxis, and only $5.3 \%$ reported having a history of $\mathrm{a}^{r} \iota \mathrm{st}_{1}$.gs without anaphylaxis. Given that in IgE-mediated systemic reactions to Hymenoptera stin $t^{1}$ e previous sting is necessary for sensitization to venom proteins, and systemic reaction: $心$ ur only with repeated stings after previous sensitization. We suspect that the reason why $\mathrm{n}_{\mathrm{n}}$ 'sı patients, contrary to expectations, did not report a history of ant sting before anaphylaxis $m_{a}, r e$ that patients had mild and non-systematic reactions to the initial stings and forgot the $r$ ila . actions due to its low severity and only recalled severe systemic reactions to ant stings.

Abou ta nily history of allergic disease in the evaluated patients, $52.6 \%$ of them had a family his ${ }^{\prime}, \mathrm{f}$ f allergic diseases. It was more common in the mother of patients $(21.1 \%)$ and the most 
common disease was asthma (21.1\%). In our cases, allergic rhinitis was the most common atopic disease in their history and asthma was the most common atopic disease in their family. ' $n$ a study by Sheffer et al. about exercise-induced anaphylaxis, they found that all patients : ad a family history of allergic rhinitis and $13 \%$ of them had a family history of asthma (36)

Skin allergy tests were performed on all our patients and all of them had positive ski ${ }^{-}$tests. We used Solenopsis Invicta extract instead of Pachycondyla sennaarensis extract in th 2 . xin tests as PS extract was unavailable. Although the PS ant sting was responsible for anaviylaxis in all cases in our study, skin tests with Solenopsis Invicta extract were positive $1_{1} a_{1}^{1}$ patients. The similarity between the materials extracted from s.invitca and PS seems to $\iota^{-} d \iota$ a positive result in skin testing.

Two patients showed anaphylactic manifestations during skin al'srgy test and were treated immediately. This indicates that although the amount of substance $\mathbf{u}_{\sim}{ }^{\prime} \mathbf{a}$ in the skin allergy test is minimal, it may lead to anaphylaxis and a well-equipped medicar $\circ$. n should be present in the test room. In a study on the risk of anaphylaxis during skin tllergy test by Licardi et al., they found that the risk of anaphylaxis during skin prick tert was less than $0.02 \%$ and with intradermal skin test was higher, and in some cases, in rac orm $\mathrm{l}$ l skin test could be fatal. Given this risk, they recommended that intradermal testing shou:' not be the first option for assessing allergies (37). The high rate of anaphylaxis in the skiı. allergy test in our study seems to be due to selected patients, all of whom have a history of ant st ng i aphylaxis.

According to the classification system of seve-ity if anaphylactic reactions presented by Brown et al. (12), we found that most anaphylactic reat rons in our patients were moderate $(57.9 \%)$ followed by severe (36.8\%) and mild (3.5\%), In I rown's study, they analyzed 1149 patients with anaphylaxis. Most of anaphylactic reactir if w $\bullet$ e severe $(68 \%)$, followed by moderate $(42 \%)$ and mild (15\%). When they focused on at ents with anaphylaxis due to insects stings, they found that most reactions were modera e (47\%), then mild (35\%) and severe (16\%). It seems that in patients with anaphylaxis due 0 insect bites, most patients show a moderate reaction.

It should be noted that in $\mathrm{h}:$ present study, Iranian allergists were asked to refer patients with a history $o^{f}$ ant sing anaphylaxis. It may reduce the actual number of cases of ant sting anaphylax:- due to the probable cases that have not been referred to an allergist. The use of Jatı nts' previous history may also affect our data recall biased. Furthermore, another $1 i_{L_{1}}$ ita $a_{2}$ of the present study is that the Samsum ant extract was not available to us fo, skin testing. Instead, we used fire ant extract. Although all of our cases had a positiv: skin test to fire ants (probably due to the similarity of the allergens in the extracts) it would be better to use Samsum ant extract for skin testing.

\section{Conclusion:}

This report - the first case series of anaphylaxis to ants in Iran and the largest report in this field in the $\mathrm{M} d \mathrm{~d}_{\mathrm{i}}$ - East. The present report shows that ant sting anaphylaxis is not uncommon in these area $\quad 1 \mathrm{lt}_{\mathrm{t}}$ - ugh fire ants (Solenopsis Invicta) are the most common cause of ant stings in Europe ard the United States, all cases of anaphylaxis in this study were due to the sting of samsum ant (Pac'vcondyla sennaarensis), a species similar to the fire ant, that is found in the south of Iran, 
the Middle East and North Africa. Allergy skin testing with fire ant extract was positive and helpful in detecting samsum ant allergies. In cases where smsum ant extract is not availabl , : " re ant extract may be a good alternative to Samsam ant skin test.

Acknowledgments: The authors would like to appreciate the valuable coope rtion of all Allergists and Clinical Immunologist of Iran in referring patients, Dr. Kam at Akbarzadeh (Medical Entomologist, Department of Medical Entomology and Vector C n nt 'n', School of Public Health, Tehran University of Medical Sciences, Tehran, Iran) for hi in ralu ıble assistance in identifying the ants' specimens and the staff of Rasool-E-Akram Hos, ita. Allergy Research Center and the private allergy clinic in Yazd.

Conflict of Interest: The authors declare absence of economic or che types of conflicts of interest regarding the article presented. 


\section{References:}

1. Sampson HA, Muñoz-Furlong A, Bock SA, Schmitt C, Bass R, Chow'nh rv BA, et al. Symposium on the definition and management of anaphylaxis: summary rep rrt. J Allergy Clin Immunol. 2005; 115 (3):584-91. doi: 10.1016/j.jaci.2005.01.009. PMID: 1_75こ908.

2. Simons FE, Ardusso LR, Bilò MB, Cardona V, Ebisawa M, El-Gamı. YN I, et al. International consensus on (ICON) anaphylaxis. World Allergy Organ J. 2014 30; ‘ ): 9 . doi: 10.1186/19394551-7-9. PMID: 24920969; PMCID: PMC4038846.

3. Shaker MS, Wallace DV, Golden DBK, Oppenheimer J, Berns - in JA, Campbell RL, et al. Anaphylaxis-a 2020 practice parameter update, syster atic review, and Grading of Recommendations, Assessment, Development and Evaluati on ( GRADE) analysis. J Allergy Clin Immunol. 2020; 145(4):1082-1123. doi: 10.1016/j.jaci.2`0.21.017.

4. Golden DB, Marsh DG, Kagey-Sobotka A, Fre 'hoff L, Szklo M, Valentine MD, et al. Epidemiology of insect venom sensitivity. Jama. 198'·2 2(2):240-4.

5. Bemanian MH, Arshi S, Nabavi M, Fallahpo' 4 Aarabi M, Karbasi M, et al. Anaphylactic Reaction to Bee Stings in the Rural Areas of For $` 2$ City: Iran's First Epidemiological Study of Hymenoptera-Induced Anaphylaxis. Jour. ^l if Pediatrics Review. 2019; 7(4):239-247. https://doi.org/10.32598/jpr.7.4.239

6. Goulet H, Huber JT. Hymenopt ra of the world: an identification guide to families. Agriculture Canada, Ottawa; 1993: Foup

7. Kemp SF, Moffitt JE, Williar $S_{S}$ 工F, Buhner WA. Expanding habitat of the imported fire ant (Solenopsis invicta): a public healt_ _ oncern. Journal of Allergy and Clinical Immunology. 2000; 105(4):683-91.

8. Brown SG, Franks RW, Brido BA, Heddle RJ. Prevalence, severity, and natural history of jack jumper ant venom dle, sy in Tasmania. J Allergy Clin Immunol. 2003; 111(1):187-92.

9. Wetterer JK. Gec srap iic spread of the samsum or sword ant, Pachycondyla (Brachyponera) senna-arensis (Hy.nenoptera: Formicidae). Myrmecological News. 2013; 18:13-8.

10. Al-Khalifa M ${ }^{\curvearrowright}$ Ahmed AM, Mashaly AMA, Al-Mekhalfi FA, Khalil G, Siddiqui MI, et al. Studies on tr - Livuribution of Pachycondyla sennaarensis (Hymenoptera: Formicidae: Ponerinae) in Saudi Aı. hia. 1. Ar-Riyadh Region. Pakistan J Zool. 2010; 42(6):707-13.

11. Fimu is FER, Ardusso LRF, Bilò MB, El-Gamal YM, Ledford DK, Ring J, et al.World allerg) c ganization guidelines for the assessment and Managementof Anaphylaxis. World Alı rgy Jrgan J. 2011; 4(2):13-37. 
12. Brown SG. Clinical features and severity grading of anaphylaxis. J Allergy Clin Immunol. 2004; 114(2):371-6.

13. Wood RA, Camargo CA Jr, Lieberman P, Sampson HA, Schwartz LB, Zitt M, Olı ns C, Tringale M, Wilkinson M, Boyle J, Simons FE. Anaphylaxis in America: the pre alune and characteristics of anaphylaxis in the United States. J Allergy Clin Immunol. 2014: 1:3(2):461-7. doi: 10.1016/j.jaci.2013.08.016. Epub 2013 Oct 18. PMID: 24144575.

14. Bilò BM, Bonifazi F. Epidemiology of insect-venom anaphylaxis. C’urr Jpi / Allergy Clin Immunol. 2008; 8:330-337.

15. Manivannan V, Campbell RL, Bellolio MF, Stead LG, Li J. Dicker WW. Factors associated with repeated use of epinephrine for the treatment of anaphy ${ }^{1} \mathrm{gx}$ is. Annals of Allergy, Asthma \& Immunology. 2009; 103(5):395-400.

16. Bilo B, Rueff F, Mosbech H, Bonifazi F, Oude-Elberink J. Dią." sis of Hymenoptera venom allergy. Allergy. 2005; 60(11):1339-49.

17. Turner PJ, Jerschow E, Umasunthar T, Lin R, Car pb 11 L E, Boyle RJ. Fatal Anaphylaxis: Mortality Rate and Risk Factors. J Allergy Clin Inn. יunol Pract. 2017; 5(5):1169-1178. doi:10.1016/j.jaip.2017.06.031

18. Aili SR, Touchard A, Escoubas P, Padula MP $\cap_{r_{1,-1}}$ J, Dejean A, Nicholson GM. Diversity of peptide toxins from stinging ant venc ${ }^{r}$.s Toxicon. 2014; 15(92):166-78. doi: 10.1016/j.toxicon.2014.10.021. Epub 2014 Oct 20. DMID: 25448389.

19. Collingwood CA, Agosti D. Formicidae ('vecta: Hymenoptera) of Saudi Arabia (part 2). Pro Entomologica, Naturhistorisches, Bas e, 1.96; 15: 300-385.

20. Al-Khalifa MS, Mashaly AMA, $\mathrm{S}_{1}{ }^{{ }^{2}} \mathrm{ir}_{1}$ ui MI, Al-Mekhlafi FA. Samsum ant, Brachyponera sennaarensis (Formicidae: Ponerin 1 e): Distribution and abundance in Saudi Arabia. Saudi Journal of Biological Sciences. 2 r, $^{-}$- 22: 575-579. doi.org/10.1016/j.sjbs.2015.05.011.

21. Abunada T, Al-Nesf MA, Thalib L, et al. Anaphylaxis triggers in a large tertiary care hospital in Qatar: a ratru ective study. World Allergy Organ J. 2018; 11(20). https://doi.org/10.1186/s4c $113 \cdot 018-0200-9$

22. AlAnazi M, AlAs ahrani M, AlSalamah M. Black ant stings caused by Pachycondyla sennaarensis: a signi icar t health hazard. Annals of Saudi medicine. 2009; 29(3):207-211

23. Tirgari S, Jist ia O. First record of the ponerine ant Pachycondyla sennaarensis (Hymenoptera: Fu-micidae) in Iran. Journal of Zoology in the Middle East. 2013; 34(1): 67-70.

24. Paknia C. Distribution of the introduced ponerine ant Pachycondyla sennaarensis (Hymens--relc. Formicidae) in Iran. Myrmecologische Nachrichten. 2006; 8:235-238.

25. 1 4 ou iel M, Firozi F. The Initiated Survey on Pachycondyla sennaarensis (Formicidae: P ..ri ze) Colonies and Its Seasonal Abundance in Abu-Musa Island, Iran. Journal Mil Med. 2014, 16(3):115-24. 
26. Nikbakhtzadeh M, Akbarzadeh K, Tirgari S. Bioecology and chemical diversity of abdominal glands in the iranian samsum ant Pachycondyla sennaarensis (Formach' 'e: Ponerinae). J Venom Anim Toxins incl Trop Dis. 2009;15(3):509-526

27. Pimiento AP, Lastra LP, Cabreros MR, Bautista AV, Cubero AG, Manuel EC is stemic reactions to wasp sting: is the clinical pattern related to age, sex and atop; Allergol Immunopathol. 2007; 35(1):10-4. doi: 10.1157/13099089.

28. Novembre E, Cianferoni A, Bernardini R, Veltroni M, Ingargiola A, om ardi E, et al. Epidemiology of insect venom sensitivity in children and its correlation ${ }^{{ }^{\circ} \mathrm{O}}$. Minical and atopic features. Clinical and Experimental Allergy. 1998; 28(7):834-838.

29. Jirapongsananuruk O, Bunsawansong W, Piyaphanee N, Visitsun ' Vichyanond P. Features of patients with anaphylaxis admitted to a י י ${ }^{\circ}$ ity hospital. Annals of Allergy, Asthma \& Immunology. 2007; 98(2):157-62.

30. Webb LM, Lieberman P. Anaphylaxis: a review of $601 \mathrm{c}$ ses. Annals of Allergy, Asthma \& Immunology. 2006; 97(1):39-43.

31. González-Pérez A, Aponte Z, Vidaurre CF, Rodrígu:7. LA. Anaphylaxis epidemiology in patients with and patients without asthma: a United 'ingdom database review. J Allergy Clin Immunol. 2010; 125(5):1098-1104.e1. doi: 10.1016/j iaci 2010.02.009.

32. Calvani M, Cardinale F, Martelli A, Muraro 1, ’ucci N, Savino F, et al. Risk factors for severe pediatric food anaphylaxis in Italy. Pedıaı : Allergy and Immunology. 2011; 22(8):8139.

33. Iribarren $\mathrm{C}$, Tolstykh IV, Miller $\mathrm{M} k$, Jisner MD. Asthma and the prospective risk of anaphylactic shock and other allergy d agn sses in a large integrated health care delivery system. Ann Allergy Asthma Immunol. 20iv; iv4(5):371-7. doi: 10.1016/j.anai.2010.03.004. PMID: 20486326.

34. Linneberg A, Berg ND, Gor 7 ez-Quintela A, Vidal C, Elberling J. Prevalence of selfreported hypersensitivity sy. ntoms following intake of alcoholic drinks. Clin Exp Allergy. 2008; 38(1):145-51. doi: 爪 1111/j.1365-2222.2007.02837.x. Epub 2007 Oct 10. PMID: 17927799 .

35. Wölbing F, Fisct $i$ J, Köberle M, Kaesler S, Biedermann T. About the role and underlying mechanisms of cofac ${ }^{\dagger}$ r in anaphylaxis. Allergy. 2013; 68(9):1085-92. doi: 10.1111/all.12193. Epub 2013 Aug 2 rv ID: 23909934.

36. Sheffer $F^{\top}$, susten KF. Exercise-induced anaphylaxis. J Allergy Clin Immunol. 1980; 66(2):106-11. ¿่าi: 10.1016/0091-6749(80)90056-1. PMID: 7400473.

37. Licrar.: G, D Amato G, Canonica GW, Salzillo A, Piccolo A, Passalacqua G. Systemic reace . ' $\therefore$ m skin testing: literature review. Journal of Investigational Allergology and Clinical Ir min logy. 2006; 16(2):75-78. 